\title{
Rating Curve Modification at Low Discharges Using Physical Model Tests
}

\author{
Shun-Chung Tsung, Jihn-Sung Lai, Yun-Ling Chen, Hau-Wei Wang \\ Taiwan Typhoon and Flood Research Institute, National Applied Research Laboratories, Taipei, Taiwan \\ Email: yinwei99@ms26.hinet.net
}

Received 4 March 2015; accepted 3 April 2015; published 7 April 2015

Copyright (C) 2015 by authors and Scientific Research Publishing Inc.

This work is licensed under the Creative Commons Attribution International License (CC BY). http://creativecommons.org/licenses/by/4.0/

(c) (i) Open Access

\begin{abstract}
Hydraulic structure is designed based on hydraulic theories or guidelines. To ensure performance, physical model tests are often used at high discharges. However, high discharge in river is rare. Physical model tests at high discharges will probably lead biased hydrological relationship. To improve hydrological relationship at low discharges, in this study, we considered the diversion rating curve of the Yuanshanzi Diversion Work. The 1/100-scaled physical model tests at low and high discharges $\left(90-1620 \mathrm{~m}^{3} / \mathrm{s}\right)$ were performed and coupled the diversion discharges of 5 flood events (2009-2010) in field. The official diversion rating curve was built only based on physical model tests at high discharges $\left(837-1620 \mathrm{~m}^{3} / \mathrm{s}\right)$. The results of physical model tests in this study suggested the official diversion rating curve should be modified considering all tests. The modifications showed the official diversion rating curve was over-estimated. A complete series of physical model tests and considering field situations, in this study, indicated expanded physical model tests and constantly field measurements were therefore necessary for hydraulic structure, which provided information to modify used hydrological relationship to fit real situations.
\end{abstract}

\section{Keywords}

Physical Model Test, Yuanshanzi Diversion Work, Rating Curve

\section{Introduction}

Hydraulic structures are always designed based on hydraulic theories or certain guidelines [1] [2] and engineers often check design requirements using physical model tests [3] [4]. Physical model tests also serve measurement data to build operation processes of hydraulic structure and hydrology analysis, such as rating curve [5] [6]. Furthermore, physical model tests show global and local flow patterns to review the original design of existed hydraulic structures. Physical model tests, therefore, can be used to provide useful and huge information to 
check hydraulic structure design before building and improve its functions after building.

For a specific hydrological condition, design discharge is often considered for hydraulic structure design. Engineers often consider high design discharges, such as extreme flow conditions, for physical model tests to guarantee proposed operation of hydraulic structure and fit design requirements. High discharges are however rare in real situations but most of hydrological relationships are built based on these measured data at high design discharges. On the contrary, low discharges occur frequently so that we should review and modify original hydrological analysis at high discharges. Insufficient measured data at low discharges lead hydrological relationships uncompleted and even improper predictions. Additionally, rare field measurement will give few field data for modifications and improvements of original hydrological relationship under different flow conditions after hydraulic structure finished. Preliminary hydrological relationships can be initiated using physical model tests at high design discharges, but hydrological relationships with good performance should be improved based on more data from physical model tests and field measurements.

In this study, we focused on diversion rating curve of the Yuanshanzi Diversion Work, that is, diversion rating curve. Section 2.1 introduces function of the Yuanshanzi Diversion Work, monitoring and present official diversion rating curve. To improve present official diversion rating curve built based on previous physical model tests at high discharges only [7], physical model tests at low discharges were then considered. Section 2.2 therefore describes the physical model and tests. Additionally, several field measurement data of diversions in typhoons and heavy rain events were also used with measurement data of physical model tests for diversion rating curve modification. Finally, Section 3 presents the modified diversion rating curve which was validated using flood events to highlight the physical model tests at low discharge.

\section{The Yuanshanzi Diversion Work and Physical Model}

\subsection{The Yuanshanzi Diversion Work}

The Yuanshanzi Diversion Work was built in 2005 and located at the upstream area of the Keelung River, Reyfong District, New Taipei City, Taiwan. Downstream area of the Keelung River, such as the Xizhi District, always suffered inundation as heavy rain occurred at upstream area before the Yuanshanzi Diversion Work built. The main function of the Yuanshanzi Diversion Work is to release flood from upstream area of the Keelung River to the sea in order to reduce flow peak discharge going through downstream area and then mitigate inundations. Figure 1 shows view of the Yuanshanzi Diversion Work including sedimentation weir, side weir, stilling pond, diversion weir, drainage tunnel and desilting sluice gates. The sedimentation weir locates at the upstream side of the Yuanshanzi Diversion Work to trap silt and avoid abrasion of concrete surface. The side weir (weir crest elevation $62.5 \mathrm{~m}$; length $184 \mathrm{~m}$ ) limits the flow and sediment through two desilting sluice gates (width $6 \mathrm{~m}$ and height $3 \mathrm{~m}$ for each gate) without diversion. The stilling pond (bed elevation $60 \mathrm{~m}$ ) locates be-

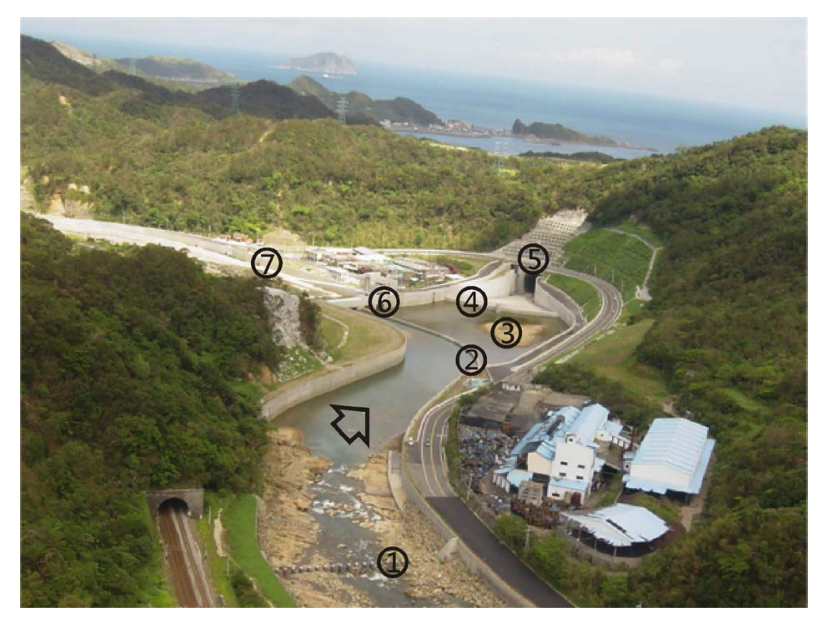

Figure 1. View of the Yuanshanzi Diversion Work: 1) sedimentation weir, 2) side weir, 3) stilling pond, 4) diversion weir, 5) drainage tunnel, 6) desilting sluice gates, 7) the Keelung River. 
tween the side weir and diversion weir which allows the extra storage for flood and sediment. The stilling pond is asymmetric. The diversion weir is a curved uncontrolled Ogee weir. A guide pier locates at the center of diversion weir. The weir length is $80 \mathrm{~m}$ and weir height is $3 \mathrm{~m}$ (weir crest elevation $63 \mathrm{~m}$ ). The maximum design diversion discharge of the Yuanshanzi Diversion Work is $1310 \mathrm{~m}^{3} / \mathrm{s}$. The design inflow discharge form upstream area of the Keelung River is $1620 \mathrm{~m}^{3} / \mathrm{s}$ and released discharge flowing into the Keelung River is then 310 $\mathrm{m}^{3} / \mathrm{s}$. The drainage tunnel is circle and the radius is $12 \mathrm{~m}$.

Figure 2 shows the components of the Yuanshanzi Diversion Work and water level sites. Flow patterns around the Yuanshanzi Diversion Work are complicated, because the work with an asymmetric stilling pond locates at curved reach of the Keelung River. To master diversion discharge, diversion rating curve is essential to be created. The form of diversion rating curve, however, definitely depends water level site. Better water lever site for diversion rating curve establishment is in front of the diversion weir, that is, in the stilling pond. There are 5 water level sites in stilling pond: LS3, LS4, MS1, MS2 and MS3. The water level site for present official diversion rating curve is LS4 that locates at left bank and in front of the diversion weir [7]. The present official diversion rating curve was established based on measurement data of previous physical model tests [4]. The equation of present official diversion rating curve was expressed as Equation (1).

$$
Q_{d}=1.6641(H-63)^{1.7606} L \text {. }
$$

where $Q_{d}$ is diversion discharge [ $\left.\mathrm{m}^{3} / \mathrm{s}\right] ; L$ is length of the diversion weir $(80 \mathrm{~m}) ; H$ is measured water level at LS4 [m].

\subsection{Physical Model Tests}

The used physical model of the Yuanshanzi Diversion Work locates at Water Resources Plan Institute, Taichung. The model scale is $1 / 100$. The physical model covers $500 \mathrm{~m}$ from upstream and downstream reaches from desiltingsluice gate. The diversion work starts from sedimentation weir to exit of drainage tunnel. Figure 3 shows the physical model. The four purposes of previous physical model tests of the Yuanshanzi Diversion Work presented as following: 1) flow measurements to review and modify original design; 2) check of the maximum diversion discharge approaching $1,310 \mathrm{~m}^{3} / \mathrm{s}$ as the maximum design inflow discharge approaching $1,620 \mathrm{~m}^{3} / \mathrm{s} ; 3$ ) avoiding drainage tunnel being pipe flow as the maximum diversion discharge reaching $1,310 \mathrm{~m}^{3} / \mathrm{s} ; 4$ ) establishment of diversion rating curve. The previous physical model tests were carried out at high inflow discharges, $Q_{i}>837 \mathrm{~m}^{3} / \mathrm{s}$, and the corresponding diversion discharges $Q_{d}$ was $581 \mathrm{~m}^{3} / \mathrm{s}$ at $Q_{i}=837 \mathrm{~m}^{3} / \mathrm{s}$. The present official diversion rating curve, Equation (1), to estimate diversion discharge was built based on physical model tests at high inflow discharges $\left(Q_{i}>837 \mathrm{~m}^{3} / \mathrm{s}\right)$.

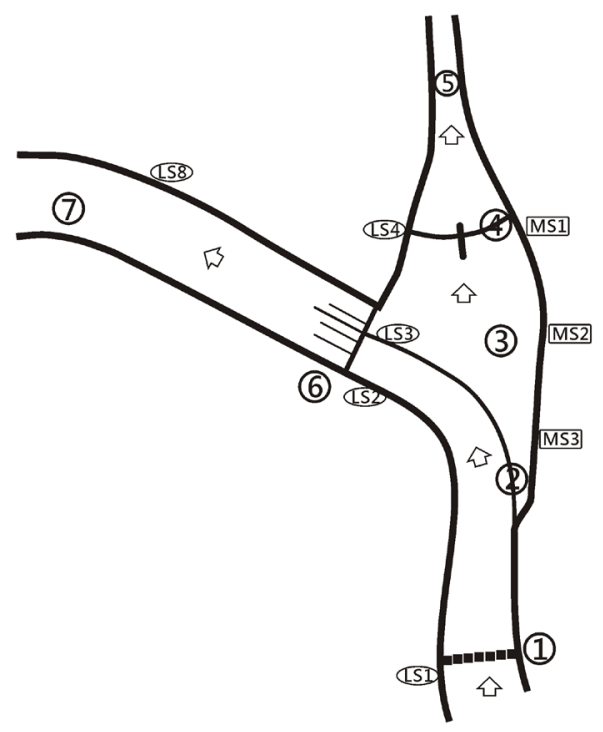

Figure 2. Sketch of the Yuanshanzi Diversion Work and water level sites; LS and MS mean water level sites. 


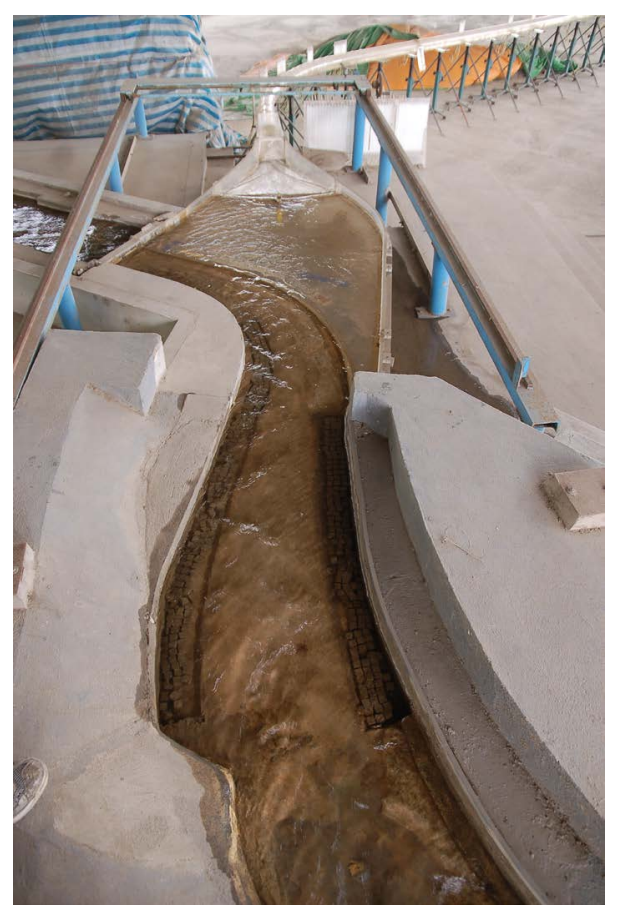

Figure 3. Physical model of the Yuanshanzi Diversion Work (scale: $1 / 100)$.

The official maximum inflow discharge and diversion discharge in the Yuanshanzi Diversion Work were $1124 \mathrm{~m}^{3} / \mathrm{s}$ and $773 \mathrm{~m}^{3} / \mathrm{s}$, individually, in typhoon Saola (2012/8/2). However, most of diversion discharges in flood events were less than $500 \mathrm{~m}^{3} / \mathrm{s}$ shown in Figure 4. The present official diversion rating curve built based on previous physical model tests at high inflow discharges therefore it should be reviewed and modified. In this study, the 1/100-scale physical model tests were carried out and the inflow discharges for physical model tests were expanded to $Q_{i}=90-1620 \mathrm{~m}^{3} / \mathrm{s}$, including high and low inflow discharges. Totally 35 tests were performed and the tests of $Q_{i}=837-1260 \mathrm{~m}^{3} / \mathrm{s}$ were repeated. Measurements in physical model tests contained 1) released discharge $Q_{o}$ flowing into the Keelung River after the Yuanshanzi Diversion Work. Released discharge $Q_{o}$ is measured by volume method at downstream storage pond of physical model. 2) water stage at LS4 in front of diversion weir using point gauge with accuracy of $0.1 \mathrm{~mm}$. 3) Diversion discharge $Q_{d}$ is calculated by $\left(Q_{i}-\right.$ $\left.Q_{o}\right)$.

In this study, the field measurements of diversion discharges and water levels at LS4 in typhoon and heavy rain events were also considered and joined with measurements of physical model tests for modifying the present official diversion rating curve. Management agency performed 5 field measurements by acoustic Doppler current profiler in typhoon and heavy rain events from 2009 to 2010. These events included 929 heavy rain (2009/9), typhoon Parma (2009/9), typhoon Lupit (2009/9), 923 heavy rain (2010/9) and typhoon Megi (2010/10). The measurement data in events of 929 heavy rain, typhoon Parma and typhoon Lupit joined the measurement data of physical model tests. Furthermore, the measurement data of 923 heavy rain and typhoon Megi were used for verification of modified diversion rating curve. To facilitate reading, the process of physical model tests and diversion rating curve modification of this study is organized and shown in Figure 5.

\section{Results and Discussions}

\subsection{Modification of Diversion Discharge}

Figure 6 shows the relationship of water depth $d_{c}(=H-63)$ and diversion discharge at LS4, including measurement data of physical model tests and flood events. Based on these data, the present official diversion rating curve (thin solid line) was modified and modified diversion rating curve (bold solid line) was expressed as Equation (2). 


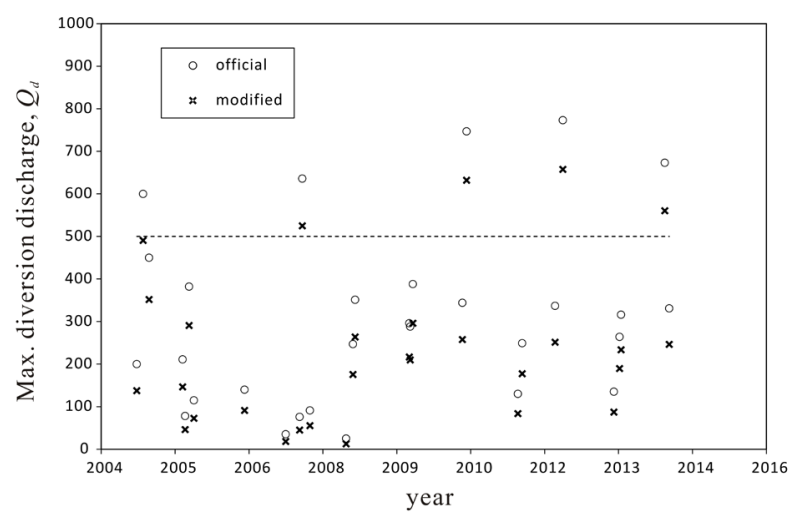

Figure 4. The official and modified maximum diversion discharge of typhoons and heavy rain events.

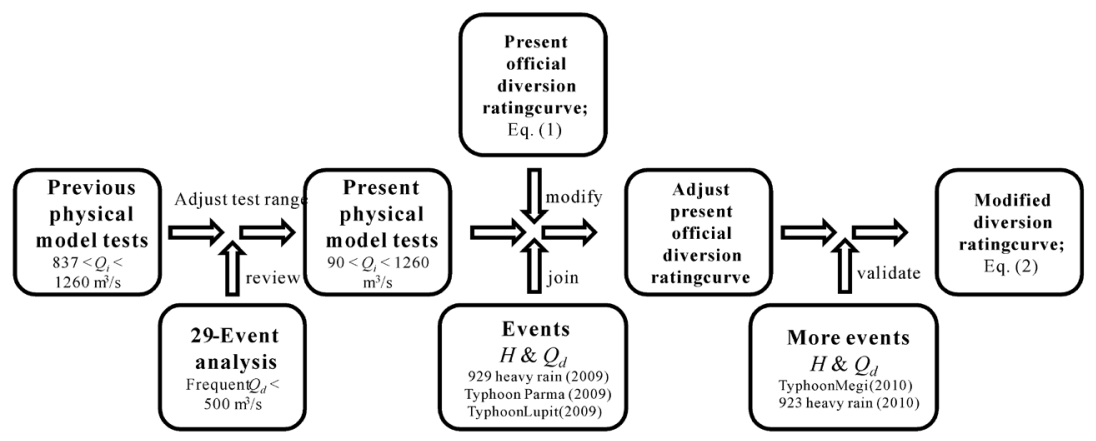

Figure 5. The process of physical model tests and diversion rating curve modification.

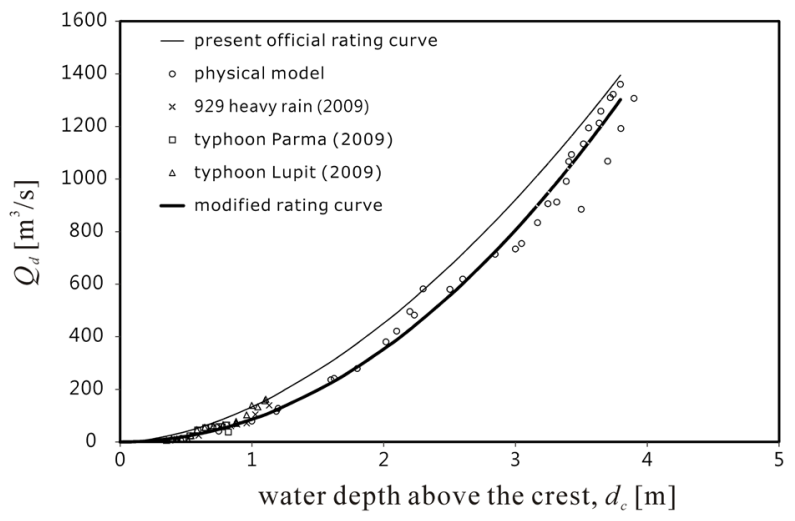

Figure 6. Relationship between water depth and diversion discharge at LS4.

$$
Q_{d}^{\prime}=1.0734(H-63)^{2.0376} L .
$$

where $Q_{d}^{\prime}$ is the modified diversion discharge.

Figure 6 illustrates that the modified diversion rating curve, considering physical model tests at low and high inflow discharge and flood events, is obviously lower than the present official diversion rating curve, only based on physical model tests at high inflow discharge. When $d_{c}=2 \mathrm{~m}(H=65 \mathrm{~m})$, the corresponding diversion discharge reduced from $458.1 \mathrm{~m}^{3} / \mathrm{s}$ to $358.9 \mathrm{~m}^{3} / \mathrm{s}$. The reduction rate was $21.7 \%$ (difference $99.2 \mathrm{~m}^{3} / \mathrm{s}$ ). When $d_{c}=$ $3 \mathrm{~m}(H=66 \mathrm{~m})$, the corresponding diversion discharge reduced from $946.7 \mathrm{~m}^{3} / \mathrm{s}$ to $831.4 \mathrm{~m}^{3} / \mathrm{s}$. The reduction rate was $12.2 \%$ (difference $115.3 \mathrm{~m}^{3} / \mathrm{s}$ ). The maximum difference between the present official and modified di- 
version rating curves was $116 \mathrm{~m}^{3} / \mathrm{s}$ and occurred at $H=65.8 \mathrm{~m}$ at LS4. When diversion discharge $Q_{d}$ was more than $450 \mathrm{~m}^{3} / \mathrm{s}$ estimated using the present official rating curve (Equation (1)), difference comparing $Q_{d}^{\prime}$ based on the modified rating curve (Equation (2)) approached $100 \mathrm{~m}^{3} / \mathrm{s}$.

Figure 7 shows the relationship of water depth $d_{c}(=H-63)$ and diversion discharge at LS4 at low inflow discharges $\left(Q_{i}<500 \mathrm{~m}^{3} / \mathrm{s}\right)$. Figure 7 also clearly indicates that the present official diversion rating curve obviously unfit those measurement data at low diversion discharges. Considerations of measurement data of physical model tests at low inflow discharges and flood events significantly influenced the shape of diversion rating curve. When $d_{c}=0.5 \mathrm{~m}(H=63.5 \mathrm{~m})$, the corresponding diversion discharge reduced from $39.9 \mathrm{~m}^{3} / \mathrm{s}$ to 20.9 $\mathrm{m}^{3} / \mathrm{s}$. The reduction rate was $46.8 \%$ (difference $18.4 \mathrm{~m}^{3} / \mathrm{s}$ ). When $d_{c}=1 \mathrm{~m}(H=64 \mathrm{~m})$, the corresponding diversion discharge reduced from $133.1 \mathrm{~m}^{3} / \mathrm{s}$ to $85.9 \mathrm{~m}^{3} / \mathrm{s}$. The reduction rate was $35.5 \%$ (difference $47.3 \mathrm{~m}^{3} / \mathrm{s}$ ). In general, the modified diversion rating curve could be used for low and high diversion discharges.

\subsection{Verification of Modified Diversion Rating Curve}

To verify the modified diversion rating curve, in this study, field measurement data of diversion discharge of typhoon Megi and 923 heavy rain were used to compare to the present official and modified diversion rating curve. Figure 8 shows the comparisons among measurement data of diversion discharge in typhoon Megi and 923 heavy rain, present official diversion rating curve and modified diversion rating curve. Figure 8 obviously indicates that measured diversion discharge of typhoon Megi and 923 heavy rain approached the modified diversion rating curve. Estimations of diversion discharge using the present official rating curve were overestimated. The verifications also indicated that expanding physical model tests and considering field measurement data of flood events could improve used hydrological relationship to fit the real flow situations.

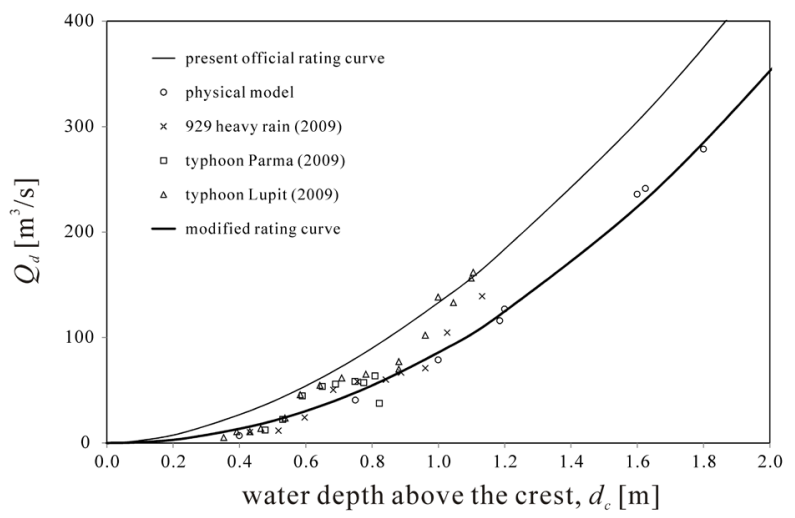

Figure 7. Relationship between water depth and diversion discharge at LS4 at low discharges.

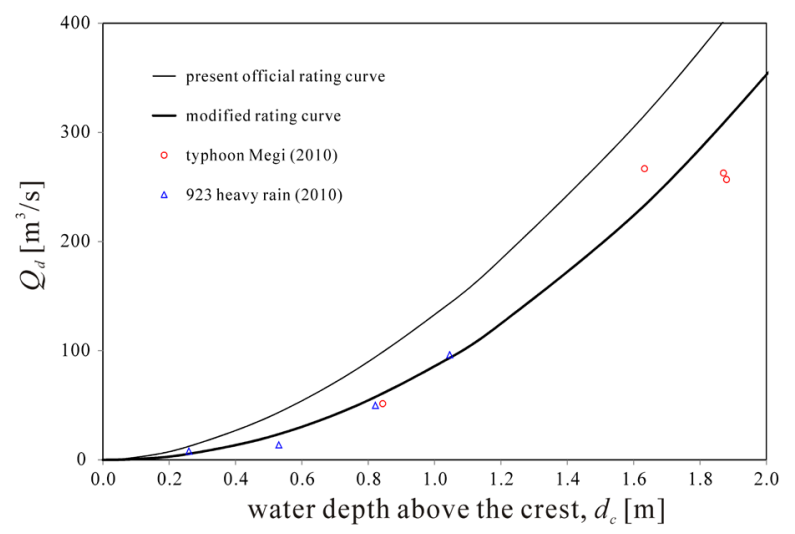

Figure 8. Comparisons of diversion discharge between flood events and rating curve. 


\section{Conclusions}

This study focused on diversion discharge of the Yuanshanzi Diversion Work. The 1/100-scale physical model tests were performed at inflow discharges of $90-1620 \mathrm{~m}^{3} / \mathrm{s}$. Several typhoons and heavy rain events were also considered. The present official diversion rating curve was established based on physical model tests at high design inflow discharges $\left(Q_{i}>837 \mathrm{~m}^{3} / \mathrm{s}\right)$. However, the diversion discharge, in general, in flood events was less than $500 \mathrm{~m}^{3} / \mathrm{s}$. This study therefore reviewed the diversion discharges at low inflow discharges $\left(Q_{i}<837 \mathrm{~m}^{3} / \mathrm{s}\right)$ and water level at LS4 in front of diversion weir. Measured water stages at LS4 and diversion discharges were organized from all physical model tests and typhoons or heavy rain events, and the present official diversion rating curve was then modified as $Q_{d}^{\prime}=1.0734(H-63)^{2.0376} L$.

This study also indicated expanding flow conditions for physical model tests and furthermore considering field measurement data of flood events gave a review to improve used hydrological relationship to fit the real flow situations. The main contribution of this study could avoid biased estimations of hydrological values, such as overestimations using present official diversion rating curve of the Yuanshanzi Diversion Work. The sufficient data from field measurements should take long time. To consider all flow conditions, numerical simulations could be used under given scenarios in the future. Efficient data therefore could support reliability of diversion rating curve.

\section{References}

[1] Transpot Association of Canada (2004) Guide to Bridge Hydraulics. Thomas Telford.

[2] Bureau of Reclamation (1987) Design of Small Dams. Department of the Interior, Washington DC.

[3] Water Resources Planning Institute (2011) Handbook of Hydraulic Model. Water Resources Agency, Nantun.

[4] Water Resources Planning Institute (2002) Hydraulic Physical Model Tests of the Yuanshanzi Diversion Work in the Keelung River. Water Resources Agency, Nantun.

[5] Kang, J., Kim, S. and Yeo, H. (2014) A Study on Physical Model Test for Cheongyeong Dam Discharge Recalculation. Engineering, 6,731-742. http://dx.doi.org/10.4236/eng.2014.611071

[6] Ghobadian, R. and Meratifashi, E. (2012) Modified Theoretical Stage-Discharge Relation for Circular Sharp-Crested weirs. Water Science and Engineering, 5, 26-33.

[7] 10th River Management Office (2005) Operation and Maintenance Plan of the Yuanshanzi Diversion Work in the Keelung River. Water Resources Agency, Nantun. 